American Journal of Pharmaceutical Education 2016; 80 (6) Article 96.

\title{
RESEARCH
}

\section{Survey of Pharmacy Schools' Approaches and Attitudes toward Curricular Integration}

\author{
Therese I. Poirier, PharmD, MPH, Jingyang Fan, PharmD, Marcelo J. Nieto, PhD \\ Southern Illinois University Edwardsville School of Pharmacy, Edwardsville, Illinois \\ Submitted May 7, 2015; accepted August 6, 2015; published August 25, 2016.
}

Objective. To identify ways in which curricular integration is addressed in US pharmacy schools, the structure of therapeutics and foundational science courses, and perceptions of the effects current curricular integration methods have on student learning.

Methods. An electronic survey was sent to academic leaders representing 131 pharmacy schools in the United States. Frequency data was tabulated and demographic analysis was performed.

Results. Respondent data represents 94 schools of pharmacy. Arranging similar content from various disciplines in a course, a skills laboratory and pharmacy practice experiences were the most common methods for achieving curricular integration. More than one half of the schools indicated that foundational sciences were integrated with therapeutics. The most common reported challenge to curricular integration was logistics.

Conclusion. Pharmacy education in the United States has evolved in addressing curricular integration in the curricula, which is consistent with changes in accreditation standards. Most pharmacy schools reported a variety of methods for achieving the intent of curricular integration.

Keywords: curricular integration, learning, foundational sciences, therapeutics, continuous quality improvement

\section{INTRODUCTION}

The 2016 Accreditation Council for Pharmacy Education (ACPE) Standards bring the idea of integrated learning to the forefront of learner-centered outcomes in pharmacy education. ${ }^{1,2}$ Specifically, the standards state that the learner should be able to develop, integrate, and apply knowledge from the foundational sciences to perform patient care and pharmacy functions. Thus, colleges and schools of pharmacy are challenged with how to achieve curricular integration. Curricular integration is a structure and process that helps students become critical thinkers and problem solvers. ${ }^{3,4}$ The focus of integration has centered on the design of pharmacotherapeutics (therapeutics) courses as this subject area is a major component for addressing the Center for the Advancement of Pharmacy Education (CAPE) Educational Outcomes. ${ }^{2}$ The status of integration in pharmacy curricula is unclear as there is more than one way to achieve curricular integration. It is also unclear what academic leaders perceive as the value of integration for student learning. The structure of integration can be horizontal, vertical, or spiral. ${ }^{5}$ Horizontal integration

Corresponding Author: Therese I. Poirier, Southern Illinois School of Pharmacy 200 University Park Drive, Room 220, Box 2000, Edwardsville, Illinois 62026-2000. Tel: 618-6505155. Fax: 618-650-5152. E-mail: tpoirie@siue.edu occurs across subjects within the same year of the program. Vertical integration is a progression of curriculum over time, and theory and practice are reenforced. Spiral integration incorporates horizontal and vertical with increasing complexity at different stages of curriculum. These structures help identify ways to achieve curricular integration.

The objectives of this study were to identify: (1) ways in which curricular integration is addressed; (2) the structure of therapeutics and foundational sciences courses; and (3) faculty perceptions of the effects currently used curricular integration methods have on student learning in pharmacy education in the United States. For purposes of this study, integration was defined as a strategy for connecting foundational sciences across disciplines and practice. ${ }^{3,4}$

\section{METHODS}

A 15-item survey was created to address the study objectives (Appendix 1). The survey was revised after piloting the instrument three times. The American Association of Colleges of Pharmacy (AACP) faculty roster was used to identify at least one academic leader from each school as the potential survey recipient. Academic leaders in pharmacy were defined as chairs of pharmaceutical sciences/medicinal chemistry/pharmacology and pharmacy 


\section{American Journal of Pharmaceutical Education 2016; 80 (6) Article 96.}

practice, and assistant/associate deans for academic affairs/ curriculum/assessment. The survey was distributed using Qualtrics (Qualtrics LLC, Provo, Utah) in September 2014; six reminders were sent over four months. The study was deemed exempt by the Southern Illinois University Edwardsville Institutional Review Board.

The survey data were analyzed using SPSS (SPSS Inc, Chicago, IL). Demographic data summarizing public vs private schools, candidate status, and geographic region of responding schools were tabulated. Frequency data describing ways schools address curricular integration, characteristics of the therapeutics course design, how foundational sciences were taught, what other disciplines/ topics were taught within therapeutics, and whether there were any proposed changes in the therapeutics structure were summarized based on number of schools. If there was conflicting information from the same school for a particular question, the data were further analyzed according to the following: (a) if there were three or more respondents from a school and there was conflicting information, then data for the question were based on the majority responses; and (b) if two respondents from the same school provided conflicting information, data for that particular question were excluded. This technique is based on taking the most frequent value. ${ }^{6}$ However, this method does not necessarily yield the true value. Yet as there were few conflicts, we were satisfied with this simple technique for data conflict resolution. Descriptive data summarizing academic discipline and position of the respondents is also presented.

Statistical analysis was conducted to determine any differences in perceptions of the effects of integration on student learning, comparing public vs private schools (Mann-Whitney U test), academic disciplines (MannWhitney U test), accreditation statuses (Kruskal-Wallis test), geographic regions (Kruskal-Wallis test), and academic positions (Kruskal-Wallis test). Chi-square was used to analyze the effects of institutional demographic data on how the design of therapeutics (integrated or not integrated) was characterized.

\section{RESULTS}

Three hundred seventy-six pharmacy academic leaders representing 131 schools were surveyed. Ninety-four schools $(71.8 \%)$ were represented in the respondent data. From those, $63.8 \%$ of 69 public schools and $80.6 \%$ of 62 private schools surveyed were represented. The respondents represented $76.7 \%$ of the 43 schools that are candidate or fully accredited $<10$ years and $69.3 \%$ of 88 schools which are fully accredited $>=10$ years. Table 1 summarizes the demographic data of the responding schools.

The most common methods schools used to address integration of science and practice were arranging similar content from various disciplines in a course according to common themes, including them in a skills laboratory or in pharmacy practice experiences (Table 2). Forty-eight schools $(51.1 \%$ of responding schools) indicated that foundational sciences such as pharmacology, medicinal chemistry, and/or pathophysiology were taught in the therapeutics courses (Table 3). Among these 48 programs, $44(91.7 \%)$ taught pharmacology within the therapeutics courses, while $79.2 \%(\mathrm{n}=38)$ taught pathophysiology, and $77.1 \%(n=37)$ taught medicinal chemistry within the therapeutics courses. Most commonly, schools taught medicinal chemistry, pharmacology, and pathophysiology in therapeutics $(60.4 \% ; n=29)$, For schools that did not teach these foundational sciences in therapeutics ( $n=46 ; 48.9 \%$ of all responding schools), 26 schools indicated that some of the sciences were taught together. This included 16 schools that taught medicinal chemistry and pharmacology together, three that taught only pharmacology and pathophysiology together, and seven that taught medicinal chemistry, pharmacology, and pathophysiology together, outside of therapeutics (Table 4). Statistical analysis of how school demographics affect course structure is presented in Table 5.

Many indicated that other core areas were included within the therapeutics course, including clinical pharmacokinetics $(n=25,26.6 \%)$, physical assessment $(n=24$, $25.5 \%$ ), and self-care and nonprescription medication therapy $(n=32,34.0 \%)$. The eight remaining schools indicated that one or more of the following were also taught in therapeutics: evidence based medicine, medication

Table 1. Demographic Data of Respondent Schools

\begin{tabular}{lcc}
\hline & $\begin{array}{c}\text { No. of Schools } \\
\text { Responding } \\
\text { (\%) }(\mathbf{n = 9 4 )}\end{array}$ & $\begin{array}{c}\text { Total No. of } \\
\text { Schools } \\
\text { Surveyed (\%) } \\
\text { (n=131) }\end{array}$ \\
\hline Pemographic & $44(46.8)$ & $699(52.7)$ \\
Priblic & $50(53.2)$ & $62(47.3)$ \\
Candidate Status & $6(6.4)$ & $8(6.1)$ \\
Fully Accredited & $27(28.7)$ & $35(26.7)$ \\
$\quad<10$ years & $61(64.9)$ & $88(67.2)$ \\
Fully Accredited & & \\
$\quad \geq 10$ years & $7(7.4)$ & $10(7.6)$ \\
New England & $9(9.6)$ & $13(9.9)$ \\
Middle Atlantic & $22(23.4)$ & $26(19.8)$ \\
South Atlantic & $8(8.5)$ & $11(8.4)$ \\
East South Central & $6(6.4)$ & $12(9.2)$ \\
West South Central & $14(14.9)$ & $20(15.3)$ \\
East North Central & $10(10.6)$ & $11(8.4)$ \\
West North Central & $9(9.6)$ & $10(7.6)$ \\
Mountain & $9(9.6)$ & $12(9.2)$ \\
Pacific & &
\end{tabular}




\section{American Journal of Pharmaceutical Education 2016; 80 (6) Article 96.}

Table 2. Methods Schools Use to Address Curricular Integration $(\mathrm{n}=94)$

\begin{tabular}{lc}
\hline Methods & $\begin{array}{c}\text { No. of Schools } \\
(\%)\end{array}$ \\
\hline Themed arrangement of & $62(66.0)$ \\
$\quad$ content & $59(62.8)$ \\
Skills laboratory & $41(43.6)$ \\
Multi-disciplinary case studies & $22(23.4)$ \\
Multi-disciplinary examinations & $47(50)$ \\
Pharmacy practice experiences & \\
$\quad$ introductory/advanced) & $7(7.4)$ \\
Senior assignment & $36(38.3)$ \\
Team-based learning/problem-based & \\
$\quad$ learning & $41(43.6)$ \\
Performance-based assessments & $7(7.4)$ \\
$\quad$ such as OSCEs & \\
$\quad$ No formal integration of science & \\
\hline OSCE = objective structure clinical examinations
\end{tabular}

therapy management, patient counseling, medication safety, microbiology, drug information, and social and behavioral aspects of illness. Fifty-two schools (55.3\%) indicated that changes to the structure of therapeutics were being proposed. This question did not specifically ask whether the changes were made to improve integration in therapeutics. When evaluating the responses to this question (question 9) vs whether foundational sciences were integrated into the therapeutics courses (question $2)$, there was no significant difference ( $p=0.956$, chisquare contingency coefficient).

One hundred forty-five individuals (38.6\%) responded to the portion of the survey on perceptions of how current integration methods at their institution affected student learning (results in Figure 1 and demographic information of respondents by discipline and academic position in Table 6). When evaluating how School and respondent demographics affected the respondents' perceptions, there was only a significant difference based on accreditation status $(p<0.05)$. Specifically, schools that had candidate status or had been

Table 3. Foundational Sciences Taught in Therapeutics $(\mathrm{n}=48,51.1 \%$ of total school respondents)

\begin{tabular}{lc}
\hline Content & $\begin{array}{c}\text { No. of } \\
\text { Schools }(\mathbf{\%})^{\mathbf{a}}\end{array}$ \\
\hline $\begin{array}{l}\text { Medicinal chemistry, pharmacology, } \\
\text { pathophysiology }\end{array}$ & $29(60.4)$ \\
Medicinal chemistry, pharmacology & $8(16.7)$ \\
Pharmacology, pathophysiology & $5(10.4)$ \\
Pharmacology & $2(4.2)$ \\
Pathophysiology & $4(8.3)$ \\
\hline
\end{tabular}

${ }^{a}$ Represent percentages of the responding 48 schools
Table 4. How Foundational Sciences are Taught if Not in Therapeutics ( $n=46,48.9 \%$ of total school respondents)

\begin{tabular}{lc}
\hline Method & $\begin{array}{c}\text { No. of } \\
\text { Schools (\%)* }\end{array}$ \\
\hline $\begin{array}{l}\text { Medicinal chemistry and pharmacology } \\
\text { together }\end{array}$ & $16(34.8)$ \\
$\begin{array}{l}\text { Pharmacology and pathophysiology } \\
\text { together }\end{array}$ & $3(6.5)$ \\
$\begin{array}{l}\text { Medicinal chemistry, pharmacology, } \\
\text { and pathophysiology together }\end{array}$ & $7(15.2)$ \\
$\begin{array}{l}\text { Medicinal chemistry, pharmacology, } \\
\text { and pathophysiology in separate courses }\end{array}$ & $20(43.5)$ \\
\hline $\begin{array}{l}\text { a Represent percentages of the responding } 48 \text { schools } \\
\text { Ren }\end{array}$
\end{tabular}

accredited for less than 10 years were more likely than schools that had been fully accredited for more than 10 years to perceive the value of integration positively in terms of learning ( $p=0.035$ for question $6, p=.021$ for question 7 , and $p=0.018$ for question 8$)$. There were no significant differences in perceptions based on academic discipline or academic position.

Seventy-four respondents provided comments on the major challenges to curricular integration. The 86 challenges reported were summarized into three major themes and an "other" category for challenges that could not be categoriezed into one of the major themes. The logistics

Table 5. Statistical Analysis of Effects of Demographics on Whether Schools Combine Foundational Sciences in Therapeutics $(\mathrm{n}=94)$

\begin{tabular}{|c|c|c|}
\hline Demographic & $\begin{array}{c}\text { Foundational } \\
\text { sciences in } \\
\text { Therapeutics, } \\
\text { N (\%) }\end{array}$ & $\begin{array}{c}\text { Foundational } \\
\text { sciences not in } \\
\text { Therapeutics, } \\
\text { N }(\%)\end{array}$ \\
\hline Public $^{\mathrm{a}}$ & $17(35.4)$ & $31(64.6)$ \\
\hline Private $^{\mathrm{a}}$ & $27(58.7)$ & $19(41.3)$ \\
\hline Candidate status ${ }^{\mathrm{b}}$ & $5(83.3)$ & $1(16.7)$ \\
\hline Accredited $<10$ yrs $^{\mathrm{b}}$ & $14(51.9)$ & $13(48.1)$ \\
\hline Accredited $\geq 10 \mathrm{yrs}^{\mathrm{b}}$ & $29(47.5)$ & $32(52.5)$ \\
\hline New England ${ }^{\mathrm{c}}$ & $4(57.1)$ & $3(42.9)^{\mathrm{c}}$ \\
\hline Middle Atlantic ${ }^{c}$ & $6(66.7)$ & $3(33.3)$ \\
\hline South Atlantic ${ }^{c}$ & $15(68.2)$ & $7(31.8)$ \\
\hline East South Central $^{\mathrm{c}}$ & $1(12.5)$ & $7(87.5)$ \\
\hline West South Centralc ${ }^{c}$ & $4(66.7)$ & $2(33.3)$ \\
\hline East North Central $^{\mathrm{c}}$ & $10(71.4)$ & $4(28.6)$ \\
\hline West North Central $^{\mathrm{c}}$ & $1(10)$ & $9(90)$ \\
\hline Mountain $^{\mathrm{c}}$ & $4(44.4)$ & $5(55.6)$ \\
\hline Pacific $^{c}$ & $3(33.3)$ & $6(66.7)$ \\
\hline
\end{tabular}




\section{American Journal of Pharmaceutical Education 2016; 80 (6) Article 96.}

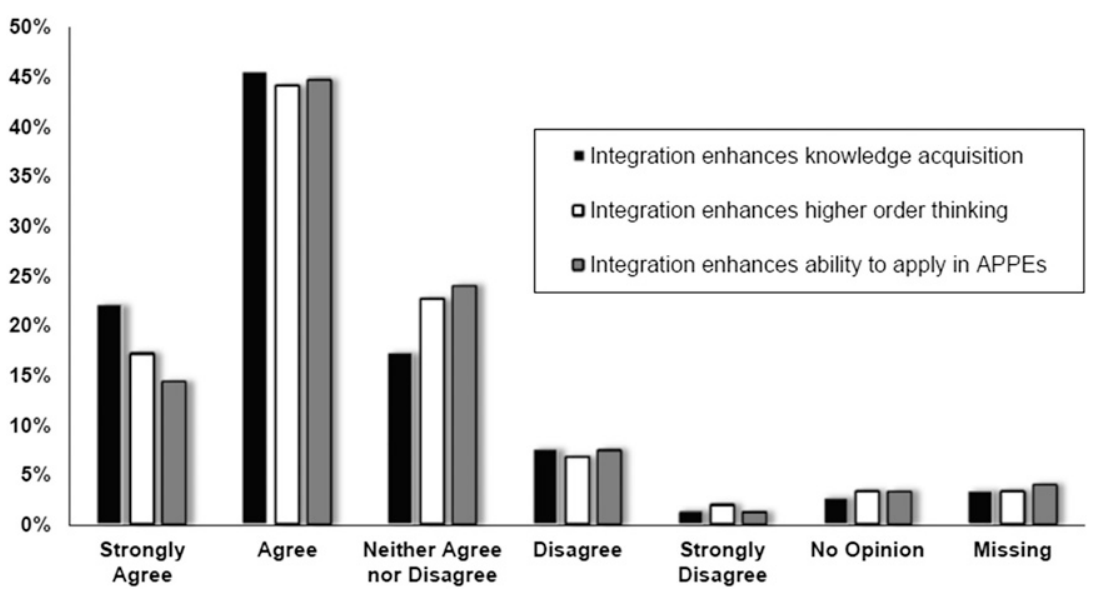

Figure 1. Faculty Perceptions of How Integration Affects Knowlege Acquision, Higher-order Thinking Ability to Apply in Advanced Pharamcy Practice Experiences (APPEs) ( $n=145$ respondents).

category $(32.6 \%)$ included scheduling, coordination, and communication issues. The workload category $(27.9 \%)$ included time and manpower. Faculty buy-in $(25.6 \%)$ included challenges of tradition and silo mindset. One recurrent challenge reported was concern that foundational sciences may be marginalized in an attempt to integrate sciences with practice.

\section{DISCUSSION}

The survey results provide a representation of AACP member schools in the United States. However, more private schools than public schools responded. Thus the data may not truly reflect the differences in public vs private schools. More pharmacy practice faculty members responded to the survey than pharmaceutical sciences faculty. This could potentially skew the perception data on how integration affects student learning.

As illustrated in Table 2, schools addressed curricular integration in a variety of ways. The data may underrepresent

Table 6. Demographic Data of Persons Responding to Perception Questions $(\mathrm{n}=145)$

\begin{tabular}{lc}
\hline Academic Discipline & $\begin{array}{c}\text { No. of } \\
\text { Respondents (\%) }\end{array}$ \\
\hline $\begin{array}{l}\text { Pharmacy practice/social \& } \\
\text { administrative sciences }\end{array}$ & $98(67.6)$ \\
$\begin{array}{l}\text { Pharmaceutical sciences } \\
\text { Academic Position } \\
\text { Chair of pharmacy practice } \\
\text { Chair of pharmaceutical sciences } \\
\text { Associate dean/asst dean/chair } \\
\text { of committee }\end{array}$ & $47(32.4)$ \\
Faculty & $40(27.6)$ \\
\hline
\end{tabular}

some methods of curricular integration, especially with the use of multidisciplinary case studies, pharmacy practice experiences, multidisciplinary examinations, team-based/ problem-based learning, and performance-based assessments as a result of conflicting information provided by respondents from the same school. Conflicting data may have been caused by different interpretation of the methods or lack of awareness. Most schools did not indicate the use of a senior assignment as a way to address curricular integration of science and practice. There is also a limited number of publications regarding use of senior assignments in pharmacy. ${ }^{7-11}$ Hobson et al's study describing a survey of pharmacy school websites revealed that only six schools out of 136 AACP member schools offered a capstone course. ${ }^{11}$ An integrative capstone course can also be a way to achieve curricular integration and may sometimes include a senior assignment. Therefore, we recommend that schools using integrative capstone course or programs and/or senior assignments assess and publish their experiences of how curricular integration is achieved.

Few schools $(7.4 \%)$ indicated that no formal integration of science and practice was done. Thus, most schools seemed to be addressing curricular integration through a variety of methods. This trend is supported by an increase in publications addressing curricular integration in pharmacy during the past decade. ${ }^{3,5,10-21}$ It is surprising that only $50 \%$ of the schools indicated that experiential education is used to address curricular integration. The low percentage might be a result of lack of awareness by respondents on how experiential education is conducted at their schools as there were at least 20 schools with conflicting data. Particularly considering that ACPE's 2007 Standard 14 stated that advanced pharmacy practice experiences (APPEs) are to integrate, apply, reinforce, and advance the knowledge developed in 


\section{American Journal of Pharmaceutical Education 2016; 80 (6) Article 96.}

the pre-APPE curriculum. ${ }^{22}$ The 2016 ACPE Accreditation Standards also challenge faculty members to emphasize foundational sciences in pharmacy practice. ${ }^{1}$ There is probably a need for more formalized assessment of whether and how curricular integration occurs in experiential education.

Regarding the structure of therapeutics courses, pharmacology, pathophysiology, and medicinal chemistry are more likely to be combined if a school integrates foundational sciences within therapeutics courses. While the model of combining foundational sciences with therapeutics courses is a method for curricular integration, anecdotal comments from colleagues indicate that if there is only sequential placement of topics, then this method may not be ideal. Comments from survey respondents suggested that more integrated case studies should be developed to enhance integration. As illustrated in Table $6,56.5 \%$ of the 46 schools that did not teach foundational sciences in therapeutics combined some of the sciences together. This survey was not designed to capture schools that structure foundational science topics with therapeutics in a temporal coordination or parallel teaching model. ${ }^{23,24}$ Thus even schools that do not combine core foundational sciences with therapeutics may have achieved curricular integration in other ways, as only $7.4 \%$ reported no formal integration of science and practice.

It is interesting that no significant differences were seen in whether foundational sciences were combined in therapeutics in terms of accreditation status. One might expect that newly accredited programs may be more likely to create integrated courses. Furthermore, there was a significant difference between public vs private schools, with a larger percentage of private schools teaching foundational sciences within therapeutics. However, public schools may not be adequately represented in the survey responses as only $63.8 \%$ of the public schools were represented. Regardless of the structure of teaching foundational sciences and therapeutics, it appears that schools adhered to principles of continuous quality improvements in curricular design as most schools indicated that proposed changes in the structure of therapeutics were being contemplated. It is encouraging to see that other disciplines, such as clinical pharmacokinetics, physical assessment, and self-care, were also taught in therapeutics. The incorporation of these areas is logical for enhancing integration of content. It is an area of curriculum redesign that could benefit from enhanced integration.

Most respondents agreed or strongly agreed that integration done at their schools enhanced acquisition of knowledge, higher-order thinking skills, and abilities to apply content and concepts during practice experiences. About $15 \%$ of respondents saw the need for improvements or were unclear of the value of integration done at their insitution. Statistical analysis did not reveal any significant differences in their perceptions based on academic discipline, position, public vs private schools, or geographic region. The only significant difference in perceptions was observed with accreditation status.

The qualitative data, which revealed the major challenges to achieve integration of learning, was summarized into four categories. The data were easily categorized into three common themes and an "others" category. The common themes are not surprising. Logistical concerns were often a reason why curricular design couldn't be implemented. Also, the time required to achieve curricular integration and the additional workload it placed on faculty members was another common barrier to optimal curricular integration. These two challenges probably affect faculty buy-in and commitment to change the approach to teaching. One recurrent challenge reported in the "other" category was the concern that there may be less emphasis placed on foundational sciences. Structuring integrated courses with appropriate weight given to the foundational sciences may address the concern that science content could potentially be marginalized in integrated courses. Further studies are needed to determine if enhanced learning of both types of content occurs when foundational sciences are integrated with clinical sciences.

\section{CONCLUSION}

Schools have evolved in addressing curricular integration, which is consistent with changes in accreditation standards. There are a variety of ways in which foundational sciences are taught relative to therapeutics. Most schools reported various methods for achieving the intent of curricular integration as required by ACPE. An ideal model may build on core knowledge over the entire curriculum, where students can apply the sciences throughout the curriculum. It is encouraging that schools adhered to principles of continuous quality improvements in curricular design.

\section{REFERENCES}

1. Accreditation standards and key elements for the professional program in pharmacy leading to the doctor of pharmacy degree. Standards 2016. Chicago, IL; 2015. https://www.acpe-accredit.org/ pdf/Standards2016FINAL.pdf.

2. Medina MS, Plaza CM, Stowe CD, et al. Center for the Advancement of Pharmacy Education 2013 educational outcomes. Am J Pharm Educ. 2013;77(8):Article 162.

3. Husband AK, Todd A, Fulton J. Integrating science and practice in pharmacy curricula. Am J Pharm Educ. 2014;78(3): Article 63.

4. Goldman E, Schroth WS. Perspective: deconstructing integration: a framework for the rational application of integration as a guiding curricular strategy. Acad Med. 2012;87(6):729-734. 


\section{American Journal of Pharmaceutical Education 2016; 80 (6) Article 96.}

5. Pearson ML, Hubball HT. Curricular integration in pharmacy education. Am J Pharm Educ. 2012;76(10):Article 204.

6. Yong-Xin Z, Qing-Zhong L, Zhao-Hui P. A novel method for data conflict resolution using multiple rules. Comput Sci Inf Syst. 2012;10 (1):215-235.

7. Vellurattil RP, Puglisi MP, Johnson CL, Slonek J. Introduction of a capstone research program in a new college of pharmacy: student perceptions. Curr Pharm Teach Learn. 2014;6(3):429-436.

8. Hirsch AC, Parihar HS. A capstone course with a comprehensive and integrated review of the pharmacy curriculum and student assessment as a preparation for advanced pharmacy practice experiences. Am J Pharm Educ. 2014;78(10):Article 192.

9. Wuller CA. A capstone advanced pharmacy practice experience in research. Am J Pharm Educ. 2010;74(10):Article 180.

10. Brown B, Skau K, Wall A. Learning across the curriculum: connecting the pharmaceutical sciences to practice in the first professional year. Am J Pharm Educ. 2009;73(2):Article 36. 11. Hobson EH, Johnston PE, Spinelli AJ. Staging a reflective capstone course to transition PharmD graduates to professional life. Am J Pharm Educ. 2015;79(1):Article 14.

12. El Sayed KA, Chelette CT. Laboratory exercises to teach clinically relevant chemistry of antibiotics. Am J Pharm Educ. 2014;78(2):Article 37.

13. Wensel TM, Broeseker AE, Kendrach MG. Design, implementation, and assessment of an integrated pharmacy applications course series. Curr Pharm Teach Learn. 2014;6(5):706-715.

14. Kolluru S, Lemke TL. An assessment model for multidisciplinary, team-taught integrated pharmacy courses. Am J Pharm Educ. 2012;76(8):Article 157.

15. Nelson M, Allison SD, McCollum M, et al. The Regis Model for pharmacy education: a highly integrated curriculum delivered by
Team-Based Learning ${ }^{\mathrm{TM}}$ (TBL). Curr Pharm Teach Learn. 2013;5 (6):555-563.

16. Henriksen B, Roche V. Creation of medicinal chemistry learning communities through enhanced technology and interdisciplinary collaboration. Am J Pharm Educ. 2012;76(8):Article 158.

17. Karimi R, Arendt CS, Cawley P, Buhler AV, Elbarbry F, Roberts SC. Learning bridge: curricular integration of didactic and experiential education. Am J Pharm Educ. 2010;74(3):Article 48. 18. Marshall LL, Nykamp D. Active-learning assignments to integrate basic science and clinical course material. Am J Pharm Educ. 2010;74(7):Article 119.

19. Barlow JW, Strawbridge JD. Teaching and assessment of an innovative and integrated pharmacy undergraduate module. Pharm Educ. 2007;7(2):193-195.

20. Fisher RC. The potential for problem-based learning in pharmacy education: a clinical therapeutics course in diabetes. $\mathrm{Am} \mathrm{J}$ Pharm Educ. 1994;58(2):183-189.

21. Wood EH, Morrison JL, Oppenheimer PR. Drug information skills for pharmacy students: curriculum integration. Bull Med Libr Assoc. 1990;78(1):8-14.

22. Accreditation Council for Pharmacy Education. Accreditation standards and guidelines for the professional program in pharmacy leading to the doctor of pharmacy degree. Chicago, IL; 2011. https://www.acpe-accredit.org/pdf/S2007Guidelines2.0_ ChangesIdentifiedInRed.pdf.

23. Beleh M, Engels M, Garcia G. Integrating a new medicinal chemistry and pharmacology course sequence into the PharmD curriculum. Am J Pharm Educ. 2015;79(1):Article 13.

24. Harden RM. The integration ladder: a tool for curriculum planning and evaluation. Med Educ. 2000;34(7):551-557.

Appendix 1. Integration Survey

For purposes of this survey, integration is defined as a strategy for connecting foundational sciences across disciplines to practice.

1. What are ways in which your institution addresses curricular integration of science and practice? (may choose more than one)

- Themed arrangement of content from various disciplines in a course (eg, organ system)

- Skills laboratory

- Multi-disciplinary case studies

- Multi-disciplinary examinations

- Pharmacy practice experiences (introductory/advanced)

- Senior assignment

- Team-based learning/problem-based learning

- Performance-based assessments such as objective structure clinical examinations (OSCEs)

- No formal integration of science and practice

- Unsure

- Other (please specify)

2. How would you characterize the pharmacotherapeutics/therapeutics course design at your institution?

a. The foundational sciences such as pharmacology, medicinal chemistry, AND/OR pathophysiology are taught in the pharmacotherapeutics/therapeutics courses.

b. The foundational sciences such as pharmacology, medicinal chemistry, AND/OR pathophysiology are not taught in the pharmacotherapeutics/therapeutics courses. 


\section{American Journal of Pharmaceutical Education 2016; 80 (6) Article 96.}

\section{If " $a$ " in \#2 is selected:}

3. Which foundational sciences are taught within the courses designated as pharmacotherapeutics/therapeutics? (may choose more than one)

- Medicinal Chemistry

- Pharmacology

- Pathophysiology

If in \#3, only "Pathophysiology" is selected:

3a. You indicated that only pathophysiology is taught within pharmacotherapeutics/therapeutics. Therefore, how are medicinal chemistry and pharmacology delivered in your curriculum?

a. Medicinal chemistry and pharmacology are taught together in one course.

b. Medicinal chemistry and pharmacology are taught in separate courses.

c. Other (Please specify)

\section{If " $b$ " in \#2 is selected:}

4. Please select how foundational sciences are delivered in your curriculum.

a. Only medicinal chemistry and pharmacology are taught together.

b. Only pharmacology and pathophysiology are taught together.

c. Medicinal chemistry, pharmacology, and pathophysiology are taught together.

d. Medicinal chemistry, pharmacology, and pathophysiology are each taught in separate courses.

e. Other (Please specify)

5. What other disciplines/areas/topics are taught within the pharmacotherapeutics/therapeutics courses, instead of a standalone course? (may choose more than one)

- Pharmacokinetics

- Physical assessment

- Self-care/nonprescription medication therapy

- Other (Please specify)

- None of the above

6. I believe integration of science and practice as done in my institution enhances acquisition of knowledge.
a. Strongly agree
b. Agree
c. Neither agree nor disagree
d. Disagree
e. Strongly disagree
f. No opinion

7. I believe integration of science and practice as done in my institution enhances higher-order thinking skills.
a. Strongly agree
b. Agree
c. Neither agree nor disagree
d. Disagree
e. Strongly disagree
f. No opinion

8. I believe integration of science and practice as done in my institution enhances student abilities to apply content and concepts during advanced pharmacy practice experiences (APPE).
a. Strongly agree
b. Agree
c. Neutral
d. Disagree
e. Strongly disagree
f. No opinion 


\section{American Journal of Pharmaceutical Education 2016; 80 (6) Article 96.}

9. Are there any proposed changes to the structure of how pharmacotherapeutics/therapeutics will be addressed in your institution currently?

a. Changes are currently being proposed or under development.

b. No changes are being proposed.

10. Which method(s) do you believe would enhance integration of learning at your institution? (may choose more than one)

- Combining foundational sciences from two or more disciplines within a course

- Using a skills laboratory

- Using multidisciplinary case studies

- Using multidisciplinary examinations

11. Identify the major challenges at your institution to achieve integration of learning.

12. Which of the following best describes your academic discipline?

a. Pharmacy practice

b. Medicinal chemistry/biochemistry

c. Pharmacology/pharmacognosy

d. Pharmaceutics

e. Social and administrative sciences

f. Other (please specify)

13. What is your current position?

a. Chair of pharmaceutical sciences

b. Chair of medicinal chemistry

c. Chair of pharmacology

d. Chair of pharmacy practice

e. Associate dean/assistant dean (curriculum, academic affairs or assessment)

f. Other (please specify)

14. Please select from the drop down list the name of your institution. 